\title{
Logistics of Medical Devices for Indigenous Health Care Attending in Remote Sites in the Brazilian Amazon Rain Forest
}

\author{
By R. P. Ferreira, F. O. Andrade, A. A. Ramos, R. Bernardes, S. J. Calil
}

Center for Biomedical Engineering, UNICAMP, Campinas, São Paulo, Brazil

\begin{abstract}
Background and Objective

In Brazil, there are 896,917 Indigenous people with 47\% dwelling in the Amazon rainforest region. To avoid expensive displacement of this population, especially for surgeries such as hernias and cataracts, the Expedicionários da Saúde nongovernmental organization (NGO) has visited this specific group 3 times per year since 2003. The visit is done through a field hospital (FH) and is supported by clinical engineering (CE). This article outlines the characteristics of logistics as well as the operation of medical and hospital devices in remote sites of the Amazon region. The object of this paper is to describe the transportation processes, installation, operation, and maintenance involved in ensuring the safe use of medical devices in one FH in the Amazon forest and to present solutions to adverse conditions encountered throughout the course of several expeditions.
\end{abstract}

\section{Material and Methods}

Initially, a survey of the processes used for transportation, installation, operation, and maintenance of medical devices was collected from 28 expeditions to the Amazon forest over a period of 10 years since the implementation of CE the team. A task-analysis process was performed to systematically identify the process used during these expeditions. To better understand the complexity and the specifics of each expedition, an evolutive planning process based on a Software Development Spiral Model was used to describe a continuous activity flow that was used to implement and test improvements in each new expedition. Besides continuous improvement, the model also takes in consideration budget solutions once all the voluntary work by the NGO is done. The efficacy of the method was evaluated from indicators of use of medical equipment, the assessment of reported adverse events, and interviews with the professional from the CE team, the users of the medical devices, and the opinion of those responsible for managing of the expedition.

\section{Results}

Several improvements were observed specifically in the transporting and installation processes, mainly through the adoption of customized packages and manuals for assembly and disassembly of the medical equipment. Further enhancements were obtained through customizations and adaptations of the devices to the hostile characteristics of the environment. Both physicians and nurses were satisfied with the performance of the devices, and few procedures for repair and calibration were required after the equipment was installed.

\section{Conclusion}

The CE team is crucial to the implementation of FHs, being essential in the management of medical technology and in the planning and operation of this type of health structure. The spiral planning method was shown to be very helpful mainly 
because it takes into account the experiences and needs of the past expeditions and for allowing the continuous improvement of the already used processes. Given the great complexity of the rainforest environment in which the technologies will be used and the unpredictability of the risks and challenges faced by the EC team the evolutionary work approach presents itself as an applicable solution when planning future expeditions.

Keywords - clinical engineering, field hospital, medical devices, Amazon Rain Forest, Expedicionarios da Saude.

Copyright (c) 2021. This is an open-access article distributed under the terms of the Creative Commons Attribution License (CC BY): Creative Commons - Attribution 4.0 International - CC BY 4.0. The use, distribution or reproduction in other forums is permitted, provided the original author(s) and the copyright owner(s) are credited and that the original publication in this journal is cited, in accordance with accepted academic practice. No use, distribution or reproduction is permitted which does not comply with these terms.

\section{INTRODUCTION}

In Brazil, there are 896,917 Indigenous people with $47 \%$ of them dwelling in a reserve forest in the Amazon region. ${ }^{1}$ Basic healthcare for this population is provided through the use of specialized health teams sent to their villages. ${ }^{2,3}$

For cases requiring specialized care, patients are sent to urban regions. ${ }^{4}$ However, this involves a significant increase in costs and great discomfort for patients because of the distance and difficulty associated with traveling to the closest specialized medical center.

To reduce displacement of patients, especially for surgeries such as hernias and cataracts (prevalence of $2.1 \%),{ }^{5}$ the non-governmental organization (NGO) Expedicionários da Saúde (Brazilian Health Expeditions) has attended to this specific population 3 times per year since 2003. There were 44 expeditions with a total of 97,060 nonsurgical patient encounters and 8,773 surgeries. ${ }^{6}$ All of the work is done by voluntary professionals who, in addition to the provided care, also assist with the assembling of the field hospital (FH) used for this service. This FH contains a specialized surgical center, sterilized material center, and ophthalmology, pediatrics, odontology, gynecology, and general clinical medicine outpatient facilities. ${ }^{7}$ The FH is defined as a mobile, self-contained, self-sufficient health care facility capable of rapid deployment and expansion or contraction to meet immediate emergency requirements for a specified period. ${ }^{8,9}$ As with permanent structures, this hospital needs medical devices for patient diagnostics and therapy. According to Finestone, the FH must be equipped appropriately to function independently. ${ }^{10}$ Therefore, it should have all necessary external resources needed to function such as medical instruments, operational material, infrastructure, and additional equipment.

Support from the clinical engineering (CE) team is crucial to the implementation of FHs and is essential to the planning, management, and support not only of the structure but also of the facilities and the medical technologies used. ${ }^{11}$

The CE team is composed of 3 engineers who travel one at a time for the expeditions and one engineer who give support to the routine work in maintenance of medical devices.

Among the diverse medical technologies involved, it is necessary to recognize their technological complexities. Consequently, the CE team is in charge of the transportation and assembling of items including electrosurgical units, physiologic monitors, imaging ultrasound, phacoemulsification machines, surgical microscopes, surgical lamps, portable laboratory, autorefractors/keratometers, pulse oximeters, colposcopes, slit lamps, and ocular biometers.

A total of 15 tons of materials and pieces of equipment for the FH are transported to their remote sites in the Amazon. ${ }^{12}$ The route includes roads, rivers, and airports with most lacking proper conditions for the landing of big-load aircraft and the transportation of delicate medical devices.

All of the material is vulnerable to weather and local environmental conditions such as high humidity, temperature, sun exposure, dust, strong winds, and impacts related to loading and unloading of boats, trucks, and aircrafts. ${ }^{13}$

The main role of technology management done by CE team is to make sure the medical devices are available and are working properly and safely. This process is done through assembling, installation, maintenance, and very importantly, by the protection of medical devices to avoid damage during transportation. ${ }^{14}$

However, the high complexity transportation of medical devices in the Amazon forest and the lack of available financial resources due to the project's often philanthropic 
origin demanded the development of a structured and evolutionary work process aiming for low-cost solutions.

\section{OBJECTIVE}

The object of this paper is to describe the transportation installation, operation, and maintenance processes used to ensure the safe use of medical devices in one $\mathrm{FH}$ in the Amazon forest and to present proposed solutions to overcome adverse conditions throughout the course of several expeditions.

\section{METHODS}

\section{Task Analysis}

Initially, a survey of the processes used for transportation, installation, operation and maintenance of medical devices was done using the method called Task Analysis.15 Data from planning, preparation, transport, and operation of medical devices were collected from 28 expeditions to the Amazon forest over a period of 10 years since the implementation of the CE team. To facilitate the visualization of these process, see Figure 1 and the survey of processes and description of stages.

Description of the stages of processes:

1.1 MD Selection: The amount, type and characteristics of the required medical devices depend on their estimated demand and on the types of patients and procedures that will need them. A contingency plan to have a 25 to $50 \%$ higher stock of medical devices is established. The corrective maintenance has a low chance of success in case of failures due to the lack of resources, such as spare parts, test equipment, tools, training, and more.

FIGURE 1. Process diagram of medical devices.

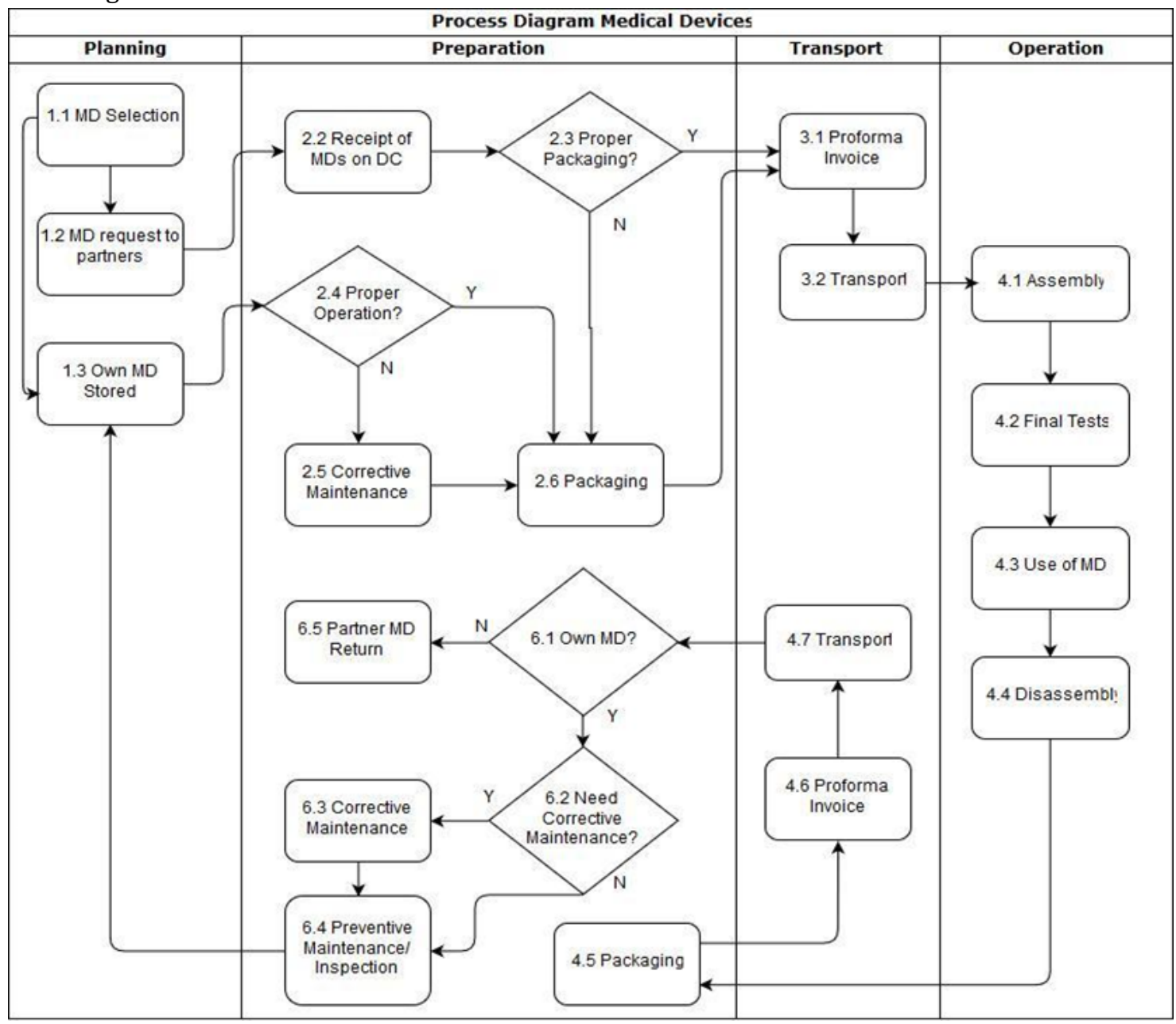


1.2 MD Request to Partners: Partner companies provide equipment that is lacking. The number of devices requested is based on demand and the number of devices currently available.

1.3 Own MD Stored: Owned MD equipment is stored in the distribution center (DC) in the southeast of Brazil. This location was selected because of better availability of companies to perform maintenance, access to better storage conditions, and easy access to equipment by the team. The management of expiration dates of accessories and materials is done at this stage.

2.2 Receipt of MDs on DC: Equipment lent by partners is delivered to the DC where it is checked after being previously tested by their providers.

2.4 Proper Operation: Before the packing stage, the NGO's equipment and accessories undergoe functional testing.

2.3 Proper Packaging: Equipment provided by partners is inspected to ensure quality and viability of the packaging and is placed in a 180-liter standardized container as necessary.

2.5 and 6.2 Corrective Maintenance: $30 \%$ of corrective maintenance is done in house and managed by the CE team. However, the loaned MDs are repaired by MD's partners.

2.6 and 4.5 Packaging: The equipment is preferably packed in foam, cut in its own format, sealed with plastic bags, and put inside the 180-liter standardized containers. The container has a weight limit of $30 \mathrm{~kg}(66.1 \mathrm{lb})$ to allow manual loading. Packages are recycled on their return.

3.1 and 4.6 Proforma Invoice: This is a checklist of the bill or goods (or items) to be included with the FH. All items receive numeric identification, sealing, and external identification with colored codes.

3.2 and 4.7 Transport: The equipment is transported by road, air, and on water (e.g., by river). Transportation from Campinas (southeast region) to Manaus (north region) can be by road or air, go through roads and highlevel airports with infrastructure, and via resources such as forklifts and warehouses. After Manaus, the load is carried by military aircraft, ferry boats, wooden boats adapted to the rain forest rivers, and sometimes on unpaved roads which are subject to quagmires and dust.
During transportation, the load can be exposed to rain. For this reason, it is protected by plastic tarps. When a load is delivered to the indigenous community or small towns that do not have proper infrastructure the unloading is manually conducted at the riverbank.

4.1 Assembly: There is a visual inspection of each MD for integrity before assembly. Assembling procedures often differ from the original manuals as they are simplified to reduce assembling errors and the limited availability of trained manual labor.

4.2 Final Tests: Before use, MDs are tested and kept working in shifts of 2 hours. This testing ensures the functioning of equipment and the generator when fully loaded.

4.3 Use of MD: The use regimen for MDs is that they will be available 13 hours a day for 6 days with the device operation monitored and controlled by the CE team.

4.4 Disassembly: The equipment is disassembled following the same procedures used in the assembly process.

6.1 and 6.5 Own MD: The partners' pieces of equipment are returned without going through internal maintenance procedures.

6.2, 6.3. and 6.4 Corrective Maintenance, Preventive and Inspection: Before storage, owned pieces of equipment go through corrective maintenance when defects have been identified; after this, equipment goes through post-repair inspection or pre-storage preventive maintenance for devices not requiring repair.

\section{Evolutionary Planning Cycle of Expeditions}

We estimated through the 28 expeditions the equipment was transported for more than 163,000 km (approx. $101,000 \mathrm{mi}$ ). Due to the highly complex environment and great diversity of problems faced in each expedition, an evolutionary and cyclic work process was developed based on the software development in the spiral (Figure 2). This model, widely used in software engineering for the development of prototypes, describes a continuous activity flow, which allows for improvements for each new expedition. ${ }^{16}$ The spiral method is similar to the PDSA (Plan, Do, Study and Act) method of continuous improvement, being chosen by the team involved in this study due to its familiarity with the method. The evolutionary cyclic work process is divided into 4 stages and 
always restarts from the last expedition where problems relating to transportation, installation, operation, and maintenance are identified.

In Stage 1 the identified problems are classified into 3 groups: technological, operational, and environmental.

After classification, each problem is analyzed, and possible solutions are proposed based on its classification in Stage 2 . The proposed solutions are evaluated and chosen according to their cost $\times$ benefit $\times$ effectiveness (Stage 3 ). This decision is influenced by limited financial resources and voluntary labor. In Stage 4, the chosen solutions are implemented and tested; if successful, they are incorporated into future expeditions.

\section{Identification of Problems Found in Expeditions}

According to the process presented previously, after each expedition, several problems are identified and registered for the improvement of future expeditions. Problems may be related to some of the following:

- Technological factors: related to the limitations of technology, the technology not being designed to the environment where it is used, such as the type of the material used in the equipment, design (size, weight, etc.), or device circuits not being compatible to the quality of energy available. ${ }^{17}$

- Environmental factors: related to the natural characteristics of the environment which impacts both the use $^{16}$ or transportation of devices, such as temperature, humidity, and condensation.

- Operational factors: related to the use of the device, such as operational, installation, transport, assembly, and disassembly errors.

Different processes of study and analysis were used to propose solutions for problems previously presented. Solutions to technology- and environment-related problems are proposed after studying device operation manuals and information from the manufacturer's websites. This study aims to identify the technical characteristics of device functioning and which critical elements can be modified and which protective measures must be implemented.

Protective measures can be implemented by improving procedures. Operational problems are studied after task analysis and solutions are implemented with improvement
FIGURE 2. Representation of the evolutionary planning cycle of expeditions.

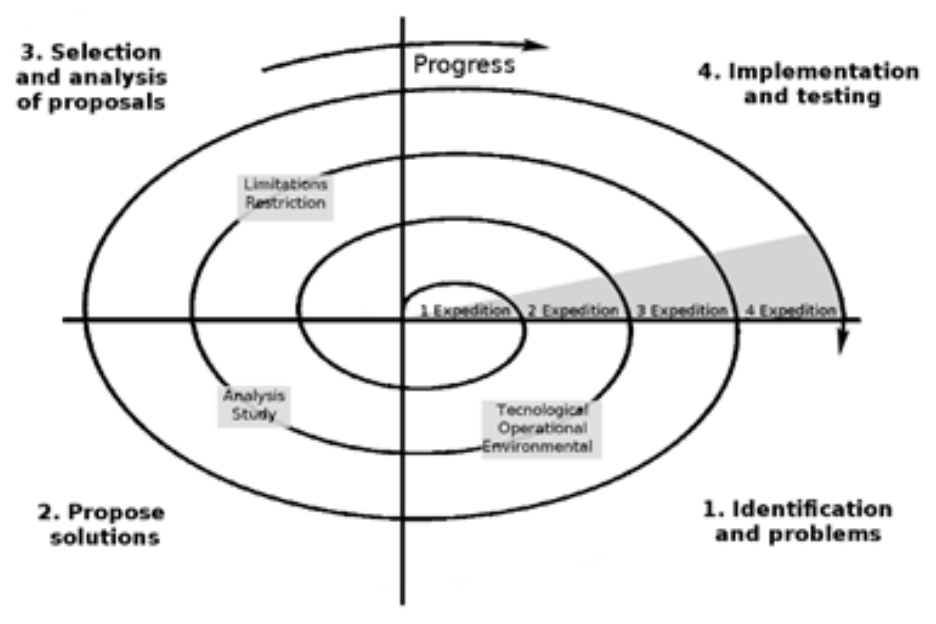

of work processes and by modifying actual device-related protocols.

\section{RESULTS}

In the first stage of the spiral cycle of evolutionary planning, problems were identified according to their characteristics.

In Table 1 it is possible to see the problems identified during a series of expeditions regarding the lack of documentation. This indicates the temporal relation between the cycle and the solution.

TABLE 1. Relation of Problems Identified According to Characteristics

Technological Factor Problems

Break of the fairing of the external part, premature break of the optic fiber, breaking of connectors during disassembly, assembly errors, bad internal contacts, equipment without battery backups, and external damage to the manufacturer's packaging.

Environmental Factor Problems

Fungi in lenses, oxidation of parts, equipment not working in ambient temperature, incompatibility of power grids, burned out equipment due to lightning, wet equipment, condensation due to excess humidity. 
Operational Factor Problems

Operational errors, equipment lacking software configuration, lack of localization of accessories/errors in checklists, lack of contingency accessories, partner equipment not working (not previously tested), lost parts during transportation, damage during transportation (error in optical measurements).

In some cases, there was uncertainty about how to classify a problem. For example, an MD that was damaged during transportation could have been classified as a technological problem for not being protected before being transported (technological) or as an operational problem for not being properly protected during transportation. Table 2 presents solutions related to problems identified in Table 1.

TABLE 2. Solutions Presented According to Problems Identified

\section{Technology-Related Solutions}

Spare accessories, corrective maintenance, change to errorfree connectors, improvements in the process of corrective maintenance, acquisition of uninterruptible power supply and change to original packages.

\section{Environment-Related Solutions}

Change in preventive maintenance protocols, equipment climate control, equipment replacement, packaging improvement, avoiding taking equipment out of climatecontrolled areas, and implementation of lightning protection.

Operational Solutions

Improvement of processes (below).

Improvements that were part of an operational problem solution are:

1.1 MD Selection: Inclusion of required MD specifications, assessment, and field tests.

1.2 MD Request to Partners: Increase in quantity of contingency equipment, accessories, and inputs.

1.3 Owned MDs Stored: Increase in quantity of strategic equipment (essential equipment for the operation of the FH or where there are loaning difficulties between the partners).

2.3 Proper Packaging: Inclusion of provider's packaging assessment. In some cases, the provider's packaging is not the most appropriate for the type of transportation used for the FHs. For example, cardboard packages that come without plastic protection, pieces of equipment without any packaging, wooden boxes without proper protection against storms.

2.4 Proper Operation: Inclusion of the testing criteria.

2.5 and 6.2 Corrective Maintenance: Inclusion of criteria for selection of maintenance providers and beginning of in-house maintenance.

2.6 and 4.5 Packaging: Improvements in the processes and packaging of materials. Some pieces of equipment have to be disassembled to fit standardized plastic boxes and for those which disassembly was not possible, waterproof wooden boxes with external protection were made with key locks and handles for manual transportation. At the bottom of the containers, $8 \mathrm{~cm}$ of foam is used to protect against impacts and water infiltration. Internal protection is achieved with medium-density foams and bubble wrap.

3.1 and 4.6 Proforma Invoice: Computerization in the process of packing lists with double checking and logistical team training in the computer system.

4.1 Assembly: Increase in instructions and assembly training, simplification of the assembly procedures, use of devices with only one option for assembly, and standardization of electrical outlets.

4.2 Final Tests: More detailed tests such as the use of an eye phantom and testing of the generators with all equipment on.

4.3 Use of MD: In loco instructions to users and infrastructure improvement for generators and electrical facilities, such improvement and standardization of power distribution boards, standardization of AC cables, exchange of single-phase generators with three-phase generators with automatic voltage control

4.4 Disassembly: More training of staff on disassembly and improvement to disassembly instructions. 
6.4 Preventive Maintenance and Inspection: Inclusion of annual preventive maintenance and obligatory inspection for every expedition.

6.5 Partner MD Return: Inclusion of the checklist of MDs that are returned along with information of any intra-expedition failures.

\section{DISCUSSION}

It can be observed that the spiral method aided the improvement of the work processes involving the management of the MDs, allowing the implementation of solutions for each new expedition cycle. However, each new proposed solution still needed to be evaluated before being added as part of the work process. And, due to the characteristics of the use of temporary FHs, this process of improvement can be very slow. One way to reduce the time needed to evaluate the proposed improvements is to apply the proposed enhancements in simulated environments. Once validated and tested they can safely be applied in the new expeditions cycle. The use of methods for risk assessment and risk mitigation during the selection and analysis of the proposals can also accelerate the process of adopting the improvements. Performing the risk analysis processes for the proposed improvements while taking into account the existing financial criteria of the expedition, the physical characteristics of the load (volume and weight), and the composition of the team at hand would considerably increase the success of the improvement proposals.

Still, some difficulties need to be assessed in each cycle, with the main difficulties being, scarce resources, continuous change of team members due to the voluntary nature of the work, and the continuous need for training, documentation, labeling, and warnings.

A critical part of the actual work process is the simplified documentation of the meetings themselves and the execution of improvements. Efforts have been made to improve the environmental conditions of the FHs, improve electrical generators, and use energy stabilizers for those more critical cases.

\section{CONCLUSIONS}

The use of the spiral method has shown positive results in the improvement of the work process, mainly within the assessment stages for every expedition, the implementation of modifications, and the posterior assessment as a continuous improvement process. The CE action done outside the boundaries of the perennial health structure is necessary for environments where patients need healthcare, with the proper support of the technology available so that such care be provided with safety and efficacy.

This support has been crucial in the attending of the isolated population in the hostile and isolated environment of the Amazon forest. Concerning the FH, the CE is responsible for transport planning and for providing the proper conditions for storage, transportation, installation, operation, and equipment disassembly, even in environments with low availability of resources.

The planning related to MD must be careful, for both supplies and accessories and also for necessary contingencies such as having a sufficient supply of replacement parts, spare pieces of equipment, and other equipment due to the geographical isolation. This isolation makes it difficult to search for solutions outside of the workplace.

Considering the unique characteristics of the FHs and the costs involved in the acquisition of specific MDs for this implementation, equipment acquisition must include the equipment standardization criteria and a reduction of device volume and weight, without any reduction in functionality.

This continuous improvement process is required because the variability found in remote sites in the Amazon challenges both transportation and implementation of FHs.

\section{ACKNOWLEDGEMENT}

Special thanks to EDS: Ricardo Ferreira (president), Marcia Abdala (general manager), Rogério Ulbrich (field engineer), João Galdino (local engineer) and Tiago Rodrigues (field engineer). 


\section{REFERENCES}

1. Instituto Sócio Ambiental. População Indígena no Brasil How many are they? Brasília, DF; ISA 2018. Available at: https://pib.socioambiental.org/en/ How_many_are_they\%3F

2. BRASIL, Ministério da Saúde, Secretaria Executiva Subsecretaria de Planejamento e Orçamento. Programa Anual de Saúde Programação Anual de Saúde (PAS) In: Objetivo 05, 1th edition. Brasília; 2018:17-20.

3. Ribeiro AA, Fortuna CM, Arantes CIS. Nursing work in an Indigenous support institution. Texto ContextoEnfermagem 2015;24(1):138-45.

4. DSEI-MG/ES. MODELO ASSISTENCIAL PARA A SAÚDE INDÍGENA. Brazil; 2004. Avaliable at: http://sis. funasa. gov. br/portal/publicacoes/pub42. pdf.

5. Rehder JR, Neto HS, Carvalho F, et al. Prevalência e causas de cegueira e baixa de acuidade visual entre grupos indígenas da amazônia legal. Arquivos Médicos do ABC 2014;25(2).

6. Brazilian Health Expeditions. Results. Campinas, SP Brazil; EDS 2019. Avaliable at: http://eds.org.br/ english/.

7. Ferreira R. $\mathrm{O}$ engenheiro clínico e os expedicionários da saúde. Sínteses: Revista Eletrônica do SIMTEC 2016;4(4):323-23.

8. WHO-PAHO Guidelines for the Use of Foreign Field Hospitals in the Aftermath of Sudden-Impact Disasters. San Salvador: Author; 2003.
9. Rossodivita A. The role of field hospitals in severe environments-guidelines to prepare and build a field hospital during a disaster. Prehospital Disaster Med 2011;26(S1):s95-s96.

10.Finestone AS. Diagnostic medical auxiliary equipment in a field hospital: experience from the Israeli delegation to the site of the Turkish earthquake at Adapazari. Militar Med 2001;166(7):637.

11.Bauld TJ. The definition of a clinical engineer. J Clin Engineer 1991;16(5):403-6.

12.Sales CRG, Sabongi ML, dos Reis VN, et al. Logística de implementação de bloco cirúrgico na floresta: atuação do enfermeiro. Revista SOBECC. 2016;21(3):162-9.

13.Instituto Nacional de Pesquisas e Espaciais. Centro de Previsão de Tempo e Estudos Climáticos. Boletim Infoclima Ano 24 de 29 de abril de 2017; Número 4. Available at:http://infoclima.cptec.inpe.br/.

14.WHO. Medical Device Donations: Considerations for Solicitation and Provision Geneva; Author; 2011.

15.Cassano-Piché A, Trbovich P, Griffin M, et al. Human factors for health technology safety: evaluating and improving the use of health technology in the real world. In: Task Analysis, 11th edition. Toronto: HumanEra, Global Centre for eHealth Innovation. University Health Network; 2015:54-62.

16. Boehm BW. A spiral model of software development and enhancement. Computer 1988;21(5):61-72.

17. McGuire N. Monitoring in the field. BJA: Br J Anaesth 2006;97(1):46-56. 
Ferreira, Andrade, Ramos, Bernardes, Calil: Logistics of Medical Devices for Indigenous Health Care Attending in Remote Sites in the Brazilian Amazon Rain Forest

\section{APPENDIX}

Examples of Transportation in the Rain Forest
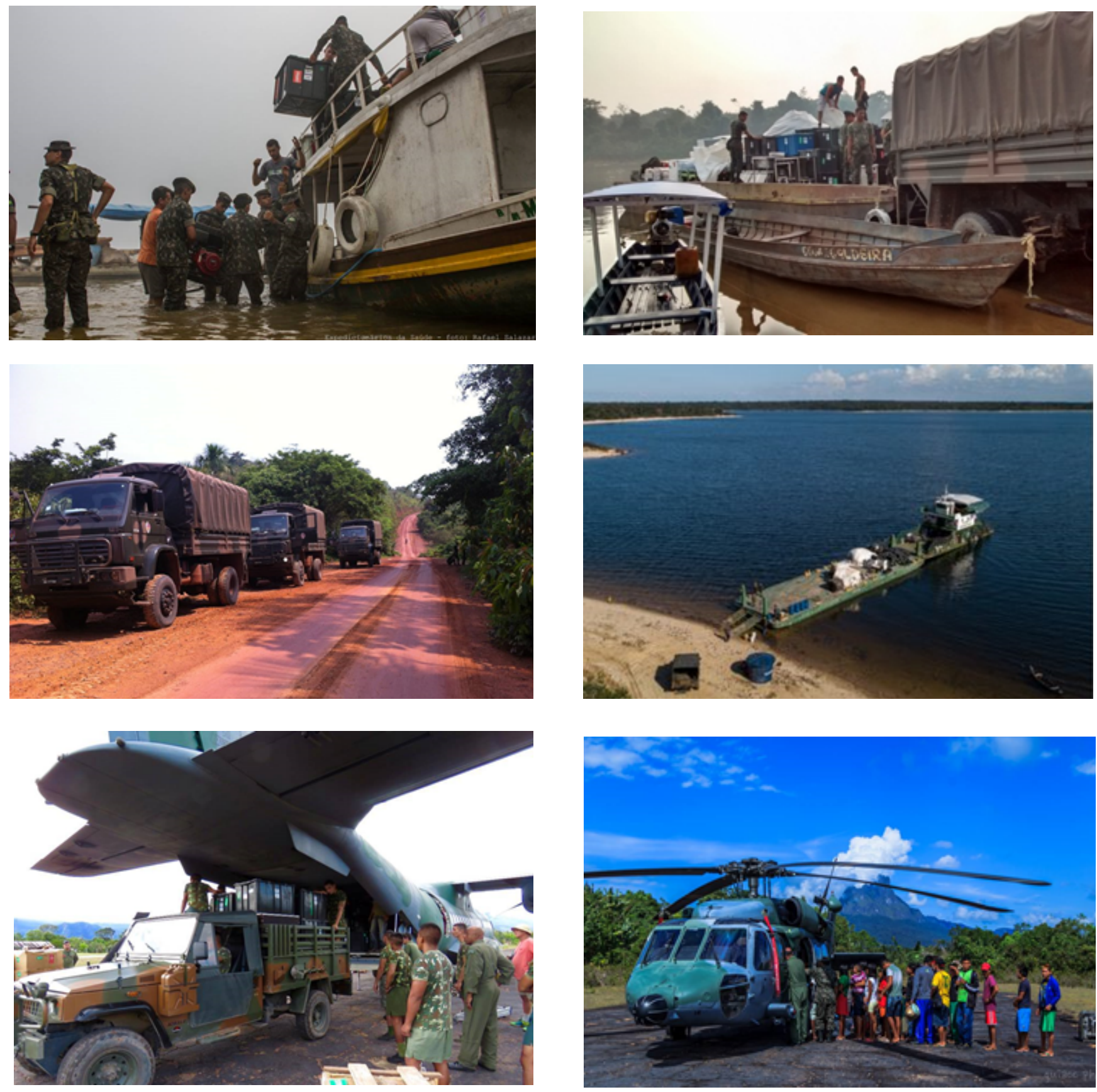
Ferreira, Andrade, Ramos, Bernardes, Calil: Logistics of Medical Devices for Indigenous Health Care Attending in Remote Sites in the Brazilian Amazon Rain Forest

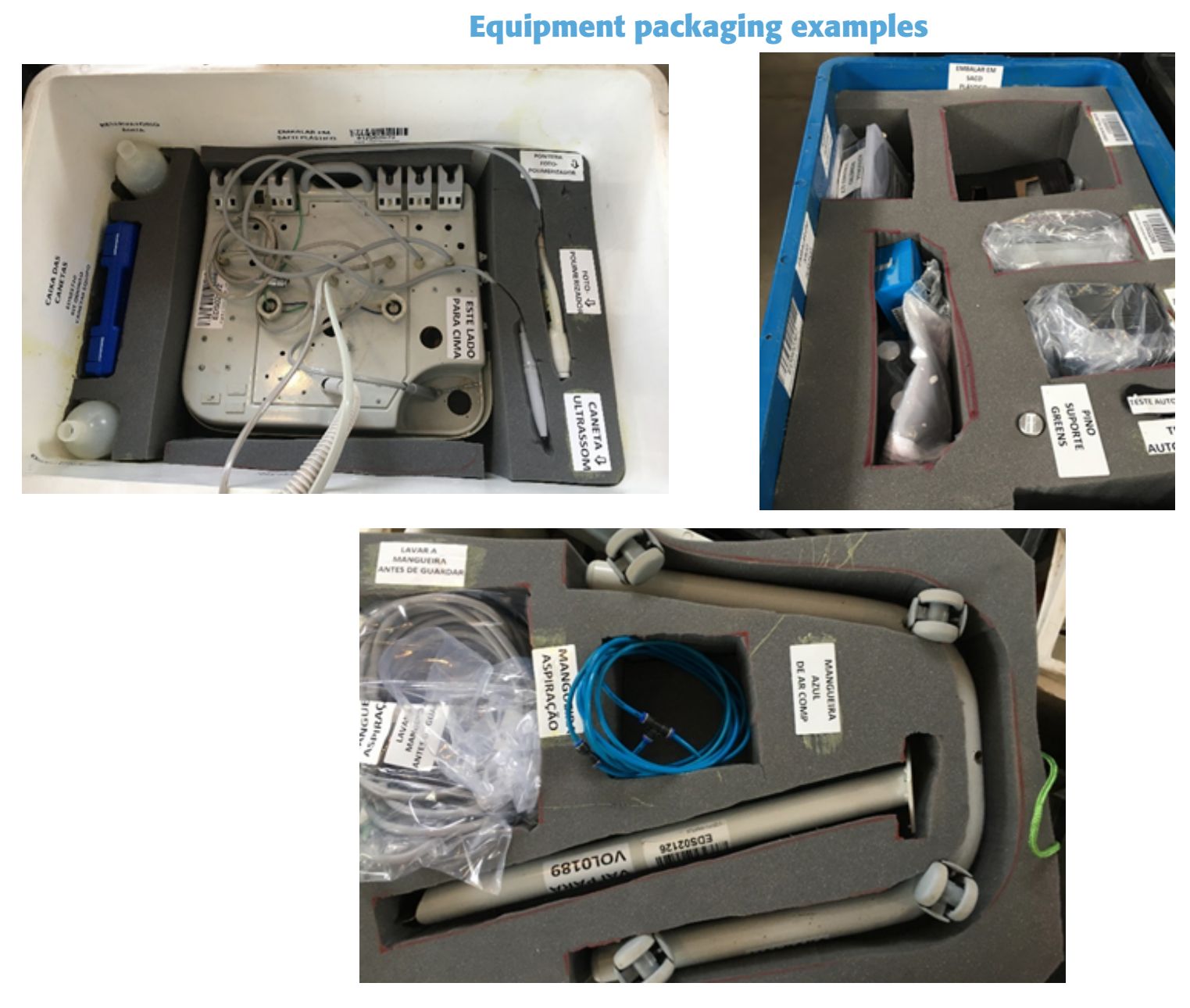

Field hospital
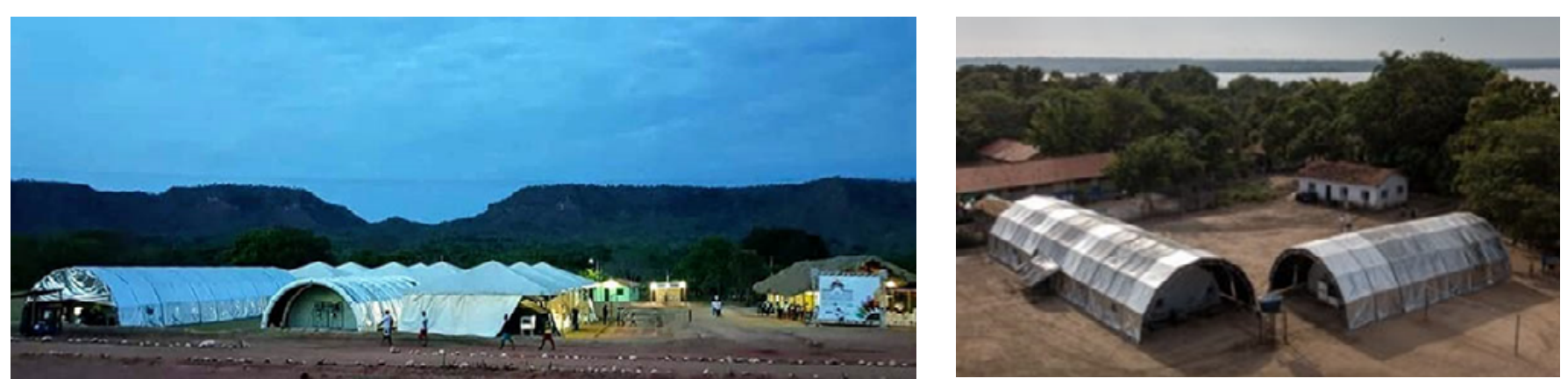


\section{Cataract surgery}

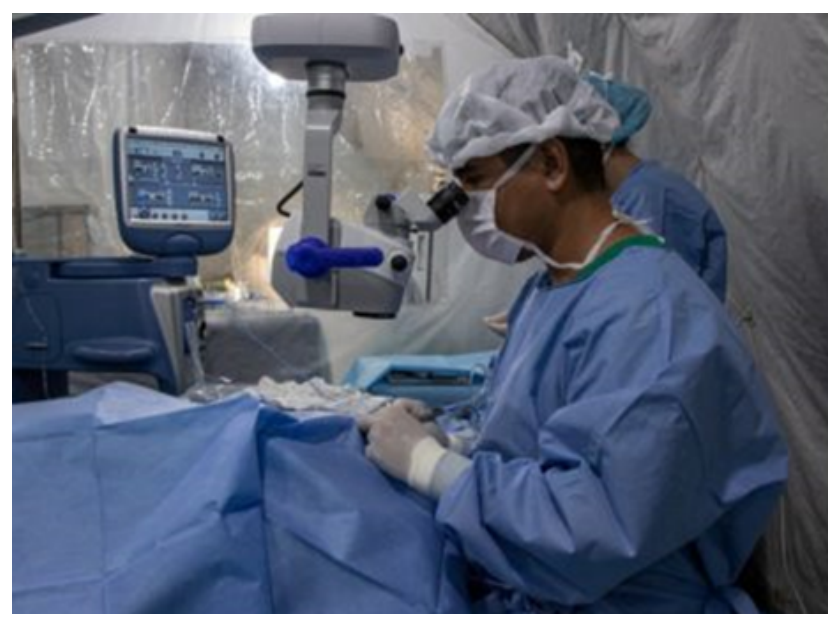

\section{General surgery}
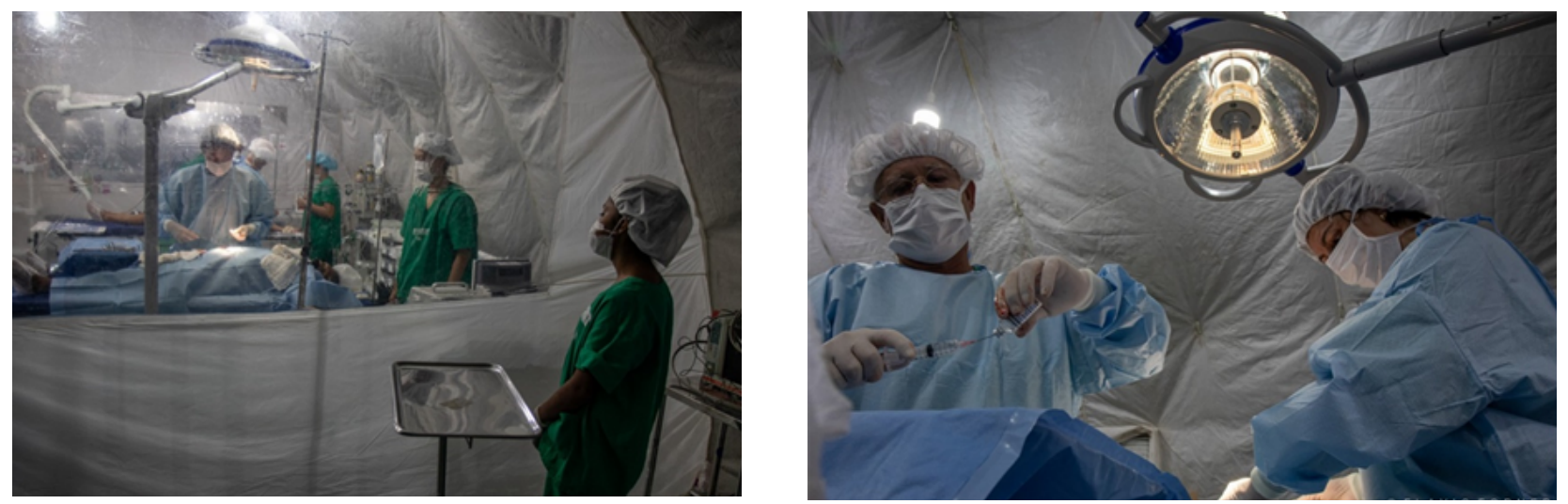

\section{EC Team}
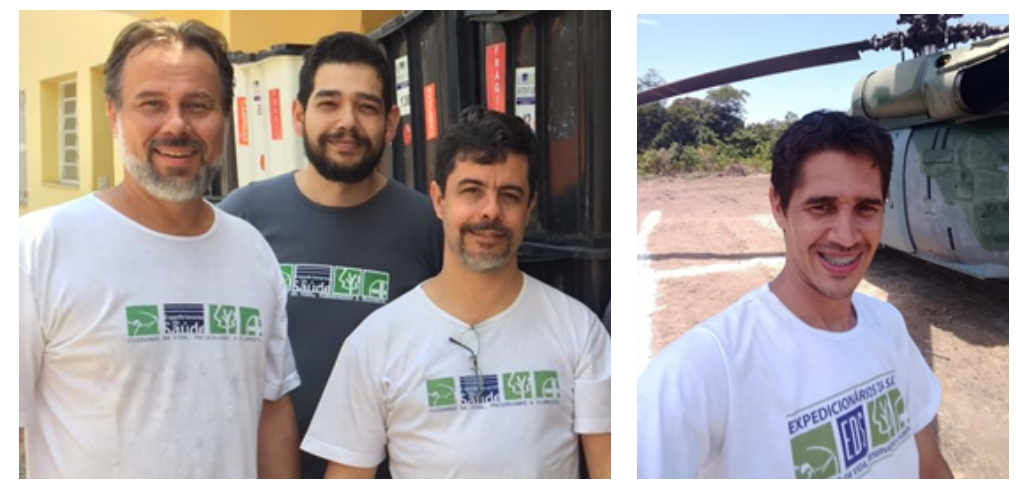

Rogerio Ulbrich, João Galdino, Ryan Ferreira and Tiago Rodrigues 